\title{
RIPK3 mediates renal tubular epithelial cell apoptosis in endotoxin-induced acute kidney injury
}

\author{
SHU ZHANG ${ }^{1,2^{*}}$, RUIZHAO LI $^{2 *}$, WEI DONG ${ }^{2}$, HUAN YANG $^{2,3}$, LI ZHANG $^{2}$, \\ YUANHAN CHEN ${ }^{2}$, WEIDONG WANG ${ }^{4},{\mathrm{CHUNLING} \mathrm{LI}^{4} \text {, YANHUA WU }}^{2}$, ZHIMING YE ${ }^{2}$, \\ XINGCHEN ZHAO ${ }^{2}$, ZHILIAN LI $^{2}$, MENGXI ZHANG $^{1,2}$, SHUANGXIN LIU $^{2}$ and XINLING LIANG ${ }^{1-3}$ \\ ${ }^{1}$ The Second School of Clinical Medicine, Southern Medical University, Guangzhou, Guangdong 510515; \\ ${ }^{2}$ Division of Nephrology, Guangdong Provincial People's Hospital, Guangdong Academy of Medical Sciences, Guangzhou, \\ Guangdong 510080; ${ }^{3}$ School of Medicine, South China University of Technology, Guangzhou, Guangdong 510006; \\ ${ }^{4}$ Institute of Hypertension, Zhongshan School of Medicine, Sun Yat-sen University, Guangzhou, \\ Guangdong 510008, P.R. China
}

Received January 18, 2019; Accepted May 23, 2019

DOI: $10.3892 / \mathrm{mmr} .2019 .10416$

\begin{abstract}
Renal tubular epithelial cell apoptosis is an important pathological mechanism of septic acute kidney injury (AKI). Endotoxin, also known as lipopolysaccharide (LPS), has a key role in septic AKI and can directly induce tubular epithelial cell apoptosis. The upregulation of receptor-interacting protein kinase 3 (RIPK3) in tubular epithelial cells has been reported in septic AKI, with RIPK3 mediating apoptosis in several cell types. In the present study, the effect of RIPK3 on endotoxin-induced AKI was investigated in mouse tubular epithelial cell apoptosis in vitro and in vivo. It was found that the expression of RIPK3 was markedly increased in endotoxin-induced AKI. Endotoxin-induced AKI and tubular epithelial cell apoptosis could be attenuated by GSK'872, a RIPK3 inhibitor. LPS stimulation also upregulated RIPK3 expression in tubular epithelial cells in a time-dependent manner. Both RIPK3 inhibitor and small interfering RNA (siRNA) targeting RIPK3 reduced LPS-induced tubular epithelial cell apoptosis in vitro. The expression of the proapoptotic protein Bax was induced by LPS and reversed by GSK' 872 or RIPK3-siRNA. The present study revealed that RIPK3 mediated renal tubular cell apoptosis in endotoxin-induced AKI. RIPK3 may be a potential target for the prevention of renal tubular cell apoptosis in endotoxin-induced AKI.
\end{abstract}

Correspondence to: Professor Xinling Liang, Division of Nephrology, Guangdong Provincial People's Hospital, Guangdong Academy of Medical Sciences, 106 Zhongshan 2 Road, Guangzhou, Guangdong 510080, P.R. China

E-mail: xinlingliang_ggh@163.com

${ }^{*}$ Contributed equally

Key words: endotoxin, acute kidney injury, renal tubular epithelial cell, apoptosis, receptor-interacting protein kinase 3

\section{Introduction}

Acute kidney injury (AKI) is a clinical syndrome characterized by the rapid loss of kidney function and abrupt kidney damage. Septic AKI is the most common complication of sepsis, which substantially increases the risk of mortality (1-3). The incidence of septic AKI is increasing, and mortality rates remain high. Septic AKI occurs in 16-25\% of patients with sepsis, with a mortality rate of $50-60 \%$ in the USA and in Europe (3). Although the clinical management of septic AKI has improved, no specific or effective treatments are available to prevent or improve this disease, as its exact mechanism remains unclear $(4,5)$. An understanding of the underlying molecular mechanisms is therefore important for the development of novel therapies to treat septic AKI.

Lipopolysaccharide (LPS), the endotoxin of gram-negative bacteria, is one of the major triggers of inflammatory responses in sepsis $(4,6,7)$. LPS not only triggers a large number of inflammatory cytokines, but can also directly induce renal tubular epithelial cell injury through the activation of Toll-like receptor 4 (TLR4). Tubular epithelial cell apoptosis is one of the characteristic changes that occurs in LPS-induced AKI $(1,4,7,8)$, and accumulating evidence has demonstrated that tubular epithelial cell apoptosis has an important role in LPS-induced AKI (6,9-11). Inhibiting tubular epithelial cell apoptosis could be an effective strategy to prevent or treat LPS-induced AKI. However, the mechanisms of LPS-induced tubular epithelial cell apoptosis are not fully understood.

Receptor-interacting protein kinases (RIPKs) are serine/threonine protein kinases that act as sensors of intracellular and extracellular stress. In total, seven isoforms that share a homologous kinase domain with different functional domains have been identified (12). These isoforms have been shown to be involved in inflammation and the cell death signaling pathway (12-14). RIPK3 was originally cloned from human fetal brain and the aortic endothelium, and subsequently characterized as an N-terminal serine/threonine kinase. RIPK3 is composed of an N-terminal kinase domain similar to other 
RIPKs, a receptor-interacting protein homotypic interaction motif that mediates protein-protein interactions and a unique C-terminal domain $(12,15,16)$. Previous studies have shown that the overexpression of RIPK3 induces apoptosis in certain cell lines (15,17-20). RIPK3 expression in renal tubular epithelial cells has been shown to be higher in murine models of septic and non-septic AKI $(21,22)$. In addition, plasma RIPK3 is elevated in critically ill trauma patients with AKI (23). These previous studies indicated that RIPK3 may be involved in LPS-induced tubular epithelial cell apoptosis. However, the role of RIPK3 in LPS-induced AKI is not well defined. The aim of the present study was to investigate the potential involvement of RIPK3 in LPS-induced tubular epithelial cell apoptosis.

\section{Materials and methods}

Animals. All animal procedures conformed to the protocols of the Guangdong Academy of Medical Sciences and were approved by the ethics committee for the experimental use of animals at Guangdong Provincial People's Hospital. C57BL/6 mice were purchased from the Nanjing Biomedical Research Institute of Nanjing University and housed at the animal center of Guangzhou Forevergen Biosciences Co., Ltd. All mice were administered a standard diet and water ad libitum, and were maintained at a temperature of $23 \pm 2{ }^{\circ} \mathrm{C}$ and an humidity of $55 \pm 5 \%$ in a controlled room with a $12 \mathrm{~h}$ light/dark cycle. When the mice reached an age of 8-12 weeks and a weight of $18-22 \mathrm{~g}$, the 18 male mice were randomly divided into three groups ( $n=6$ per group): i) Control group, mice were intraperitoneally injected with vehicle (saline); ii) LPS group, mice were intraperitoneally injected with $10 \mathrm{mg} / \mathrm{kg}$ LPS; iii) LPS + GSK'872 group, mice were intraperitoneally injected with $5 \mu \mathrm{M} / \mathrm{kg}$ GSK'872 for 30 min prior to LPS treatment. All mice were observed for $24 \mathrm{~h}$ after LPS/saline treatment and were then euthanized. Blood was collected through a puncture in the inferior vena cava and the kidneys were harvested.

Renal function test. Renal function was assessed by detecting serum creatinine ( $\mathrm{SCr}$ ) levels using a QuantiChrom ${ }^{\mathrm{TM}}$ Creatinine Assay kit (BioAssay Systems) and blood urea nitrogen (BUN) using a QuantiChrom ${ }^{\mathrm{TM}}$ Urea Assay kit (BioAssay Systems), according to the manufacturer's protocols.

Periodic acid-Schiff (PAS) staining of kidney tissues. Kidney tissues were fixed with $4 \%$ paraformaldehyde at $4^{\circ} \mathrm{C}$ for $24 \mathrm{~h}$ and embedded in paraffin. Paraffin blocks were cut into $4 \mu \mathrm{m}$ thick sections. Paraffin tissue sections were deparaffinized using xylene and descending ethanol series (100, 95, 85 and $70 \%$ ). Each incubation was performed for $10 \mathrm{~min}$ at room temperature. The sections were washed for $5 \mathrm{~min}$ in distilled water at room temperature, and the PAS Stain Kit (cat. no. ab150680; Abcam) was used. Sections were immersed in the periodic acid solution (included in the PAS kit), for $10 \mathrm{~min}$ at $20^{\circ} \mathrm{C}$. Tissue sections were then washed four times with distilled water and immersed in Schiff's solution (included in the PAS kit) for $30 \mathrm{~min}$ at room temperature and then washed using tap water for $15 \mathrm{~min}$ at room temperature. Slides were stained with hematoxylin for 2-3 $\mathrm{min}$ at room temperature.
Slide were washed with distilled water, dehydrated through ascending ethanol series $(80,95$ and $100 \%$ ) for $5 \mathrm{~min}$ at room temperature, cleared by xylene for $5 \mathrm{~min}$ at room temperature and sealed with neutral balsam (cat. no. G8590; Beijing Solarbio Science \& Technology Co., Ltd.). Tubular epithelial cell vacuolar deformation/hypertrophy and lumen occlusion occurred during renal tubular injury. The areas of the tubular epithelial cell vacuolar deformation, loss of brush border, tubular dilation, cast formation and cell lysis were calculated. A score of 0 indicated no change; scores of 1 , 2,3 or 4 indicated an injury section involving $<25,25-50$, $50-75$ or $>75 \%$ of the area, respectively. A minimum of six different fields of vision were randomly selected using a light microscope (magnification $\mathrm{x} 400$ ) and an average score was calculated (24).

Electron microscopy. Renal tissue specimens were fixed with $2.5 \%$ glutaraldehyde, $4 \%$ paraformaldehyde and $0.02 \%$ picric acid in $0.1 \mathrm{M}$ cacodylate buffer ( $\mathrm{pH}$ 7.2) overnight at $4^{\circ} \mathrm{C}$. Following washing three times in cacodylate buffer, specimens were post-fixed with $1 \%$ osmium tetroxide and $1.5 \%$ potassium ferrocyanide for $2 \mathrm{~h}$ at $4^{\circ} \mathrm{C}$ and then washed three times in cacodylate buffer. The specimens were dehydrated using a graded series of ethanol (50, 70, 80, 90 and $100 \%$ ) and $100 \%$ propylene oxide for 15-20 min at each step, and then embedded in SPI-PON 812 (Structure Probe, Inc.) for $12 \mathrm{~h}$ at $37^{\circ} \mathrm{C}, 45^{\circ} \mathrm{C}$ for $12 \mathrm{~h}$ and $60^{\circ} \mathrm{C}$ for $48 \mathrm{~h}$. Ultrathin sections were cut into 50-60 nm using Accu-Edge high-profile blades (cat. no. 4685; Sakura Finetek Japan Co., Ltd.) on a Microm HM 355s (Thermo Fisher Scientific, Inc.). Sections were stained with $3 \%$ uranium acetate and lead citrate at $4^{\circ} \mathrm{C}$ overnight. Renal tissue ultrastructure was observed using a transmission electron microscope (JEM-100CX; JEOL Ltd.). Images were recorded using a Veleta $2 \mathrm{~K}$ digital camera (Olympus-SIS; Olympus Corporation).

TUNEL staining. TUNEL staining was performed using the in situ Cell Death Detection kit (Roche Diagnostics GmbH). Frozen tissue sections were placed on coverslips and fixed in $4 \%$ paraformaldehyde for $20 \mathrm{~min}$ at room temperature. Following washing in PBS, frozen tissue sections were blocked with $3 \% \mathrm{H}_{2} \mathrm{O}_{2}$ in methanol for $10 \mathrm{~min}$ at room temperature and then permeabilized with $0.1 \%$ Triton $\mathrm{X}-100$ in $0.1 \%$ sodium citrate for $10 \mathrm{~min}$ at room temperature. The tissue sections were incubated with TUNEL reaction mixture for $60 \mathrm{~min}$ at $37^{\circ} \mathrm{C}$ in a humidified atmosphere in the dark. Following washing three times with PBS, tissue sections were stained with $1 \mu \mathrm{g} / \mathrm{ml}$ DAPI for $5 \mathrm{~min}$ at room temperature. Using a confocal fluorescent microscope (Nikon Eclipse Ni-E; Nikon Corporation), 10-20 fields were captured for each kidney section ( $n=6$ in each group) and positively stained cells were quantified. Images were analyzed using ImageJ software (version 1.49; National Institutes of Health).

Reverse transcription-quantitative PCR (RT-qPCR). Total RNA was extracted from cultured cells using TRIzol ${ }^{\circledR}$ reagent (Invitrogen; Thermo Fisher Scientific, Inc.), according to the manufacturer's instructions. RT was carried out using a PrimeScript RT Reagent kit (Takara Bio, Inc.) according to the manufacturer's protocol. The cDNAs were subjected to 
qPCR using a Power SYBR Green PCR Master Mix (Takara Bio, Inc.). Data were analyzed using the $2^{-\Delta \Delta C q}$ method (25) and GAPDH was used as the internal control. Primer sequences are listed in Table I.

Cell culture and reagents. Mouse proximal renal tubular epithelial primary cells were purchased from Cell Biologics, Inc. The cells were cultured in DMEM/F12 medium (Gibco; Thermo Fisher Scientific, Inc.) supplemented with $10 \%$ FBS (Gibco; Thermo Fisher Scientific, Inc.) in a humidified atmosphere of $5 \% \mathrm{CO}_{2}$ at $37^{\circ} \mathrm{C}$ and passaged every 3-4 days. The cells were treated with $40 \mu \mathrm{g} / \mathrm{ml}$ LPS at different times $(6,12,24$ and $48 \mathrm{~h})$. Cells were treated with $0.5 \mu \mathrm{M}$ GSK'872 (RIPK3 inhibitor; Selleck Chemicals) $1 \mathrm{~h}$ prior to the addition of $40 \mu \mathrm{g} / \mathrm{ml}$ LPS for $24 \mathrm{~h}$. Control cells were treated with an equal volume of DMSO. Cells were transfected with $50 \mathrm{nM}$ negative control small interfering RNA (siRNA) or 50 nM RIPK3 siRNA (Guangzhou RiboBio Co., Ltd.) by Lipofectamine 2000 (Thermo Fisher Scientific, Inc.) for $48 \mathrm{~h}$ before being exposed to LPS. The sequences of the siRNAs used in the present study are listed in Table II.

Western blot analysis. Total protein was extracted from kidney tissue using RIPA lysate buffer (Beyotime Institute of Biotechnology) supplemented with protease inhibitor cocktail tablets (Roche Diagnostics $\mathrm{GmbH}$ ). The mouse proximal renal tubular epithelial cells were lysed using RIPA lysate buffer supplemented with protease inhibitor mixture (Beyotime Institute of Biotechnology). Protein concentrations were determined using a bicinchoninic acid protein assay kit (Thermo Fisher Scientific, Inc.). Proteins were separated by SDS-PAGE on $10-15 \%$ gels, with loaded with $30 \mu \mathrm{g}$ of total protein. Gels were transferred onto PVDF membranes. The membranes were blocked with 5\% non-fat dry milk in TBS-Tween 20 (TBST) for $1 \mathrm{~h}$ at room temperature. PVDF membranes were incubated overnight at $4^{\circ} \mathrm{C}$ with antibodies against $\beta$-actin $(1: 1,000$; cat. no. 8457; Cell Signaling Technology, Inc.), RIPK3 (1:1,000; cat. no. ab56164; Abcam), cleaved caspase-3 (C-caspase-3; 1:1,000; cat. no. 9664; Cell Signaling Technology, Inc.) and Bax (1:1,000; cat. no. 2772; Cell Signaling Technology, Inc.). Membranes were then incubated with a horseradish peroxidase-conjugated goat anti-rabbit secondary antibody $(1: 2,000$; cat. no. 7074; Cell Signaling Technology, Inc.) for $1 \mathrm{~h}$ at room temperature. Following washing in TBST, protein bands were visualized using Pierce ${ }^{\mathrm{TM}}$ ECL Western Blotting Substrate (Thermo Fisher Scientific, Inc.) and band intensity was quantified using Tanon software (version 5200; Tanon Science and Technology Co., Ltd.).

Cell apoptosis detection. An Annexin V/propidium iodide (PI) double staining assay (Nanjing KeyGen Biotech Co., Ltd.) was used to determine the level of apoptosis, according to the manufacturer's instructions. Medium was removed from the cells following the different treatments for $24 \mathrm{~h}$. Cells were washed three times with cold PBS and digested with $0.25 \%$ EDTA-free trypsin. Cells were centrifuged for $5 \mathrm{~min}$ at $805 \mathrm{x} \mathrm{g}$ at $4^{\circ} \mathrm{C}$ and the supernatant was discarded. Cells were resuspended in $500 \mu \mathrm{l} 1 \mathrm{X}$ binding buffer and $5 \mu \mathrm{l}$ Annexin V-FITC was added. The mixture was incubated for $15 \mathrm{~min}$ in the dark and $5 \mu \mathrm{l}$ PI was subsequently added
Table I. Primers for reverse transcription quantitative PCR.

\begin{tabular}{ll}
\hline Gene & \multicolumn{1}{c}{ Sequence $\left(5^{\prime}-3^{\prime}\right)$} \\
\hline GAPDH & Forward AGGTCGGTGTGAACGGATTTG \\
& $\begin{array}{l}\text { Reverse TGTAGACCATGTAGTTGAGGTCA } \\
\text { RIPK3 }\end{array}$ \\
& Forward TGGGCCTGCTAAGATGGCT \\
& Reverse CTGCCAGAGTGTGGATTTGGT
\end{tabular}

RIPK3, receptor-interacting protein kinase 3.

Table II. siRNA sequences.

\begin{tabular}{lc}
\hline Name & Sequence (5'-3') \\
\hline RIPK3 siRNA-1 & GCAGGAAATTTCAGGCCAA \\
RIPK3 siRNA-2 & CCTGCTGAATTTCAAGAAA
\end{tabular}

siRNA, small interfering RNA; RIPK3, receptor-interacting protein kinase 3 .

at $4^{\circ} \mathrm{C}$. The solution was incubated for a further $5 \mathrm{~min}$ in the dark at $4^{\circ} \mathrm{C}$. Cells were analyzed using a flow cytometer (BD Biosciences).

Statistical analysis. Results are presented as the mean \pm SEM. All experiments were performed at least in triplicate. Statistical analysis of the data was performed using SPSS 20.0 (IBM Corp.). Comparisons among multiple groups were performed using one-way ANOVA and the least square difference was used as a post hoc test. $\mathrm{P}<0.05$ was considered to indicate a statistically significant difference.

\section{Results}

Effects of LPS on renal function and pathology. After $6 \mathrm{~h}$ of LPS intervention, mice exhibited symptoms of decreased food intake and increased salivation or tear secretion, consistent with sepsis. These symptoms markedly increased over time (data not shown). Renal function and pathology were detected $24 \mathrm{~h}$ after LPS intervention. As shown in Fig. 1A, compared with the control group, LPS-treated mice showed significantly higher levels of $\mathrm{SCr}(1.26 \pm 0.13 \mathrm{mg} / \mathrm{dl}$ in the LPS group vs. $0.44 \pm 0.03 \mathrm{mg} / \mathrm{dl}$ in the control group; $\mathrm{P}<0.001)$ and BUN $(80.59 \pm 3.74 \mathrm{mg} / \mathrm{dl}$ in the LPS group vs. $37.22 \pm 2.50 \mathrm{mg} / \mathrm{dl}$ in the control group; $\mathrm{P}<0.001)$. As shown in Fig. 1B, the pathological injury of the kidney, including vacuolar deformation, swelling of tubular epithelial cells and tubular lumen stenosis, mainly occurred in the cortex and outer stripe of the outer medulla in the LPS group. The tubular injury score of the LPS group was significantly higher than that in the control group $(3.29 \pm 0.06$ in the LPS group vs. $0.68 \pm 0.06$ in the control group; $\mathrm{P}<0.001$; Fig. $1 \mathrm{C}$ ). In addition, mitochondrial injury in tubular epithelial cells, demonstrated by the disorder or disappearance of crista, and mitochondrial swelling and deformation, was aggravated in the LPS group compared with the control group (Fig. 1D). 

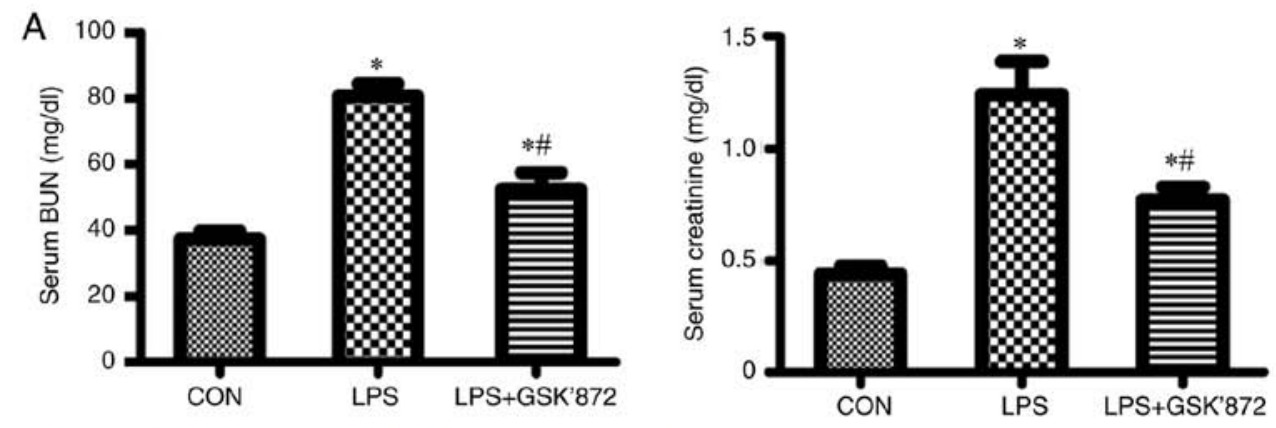

B
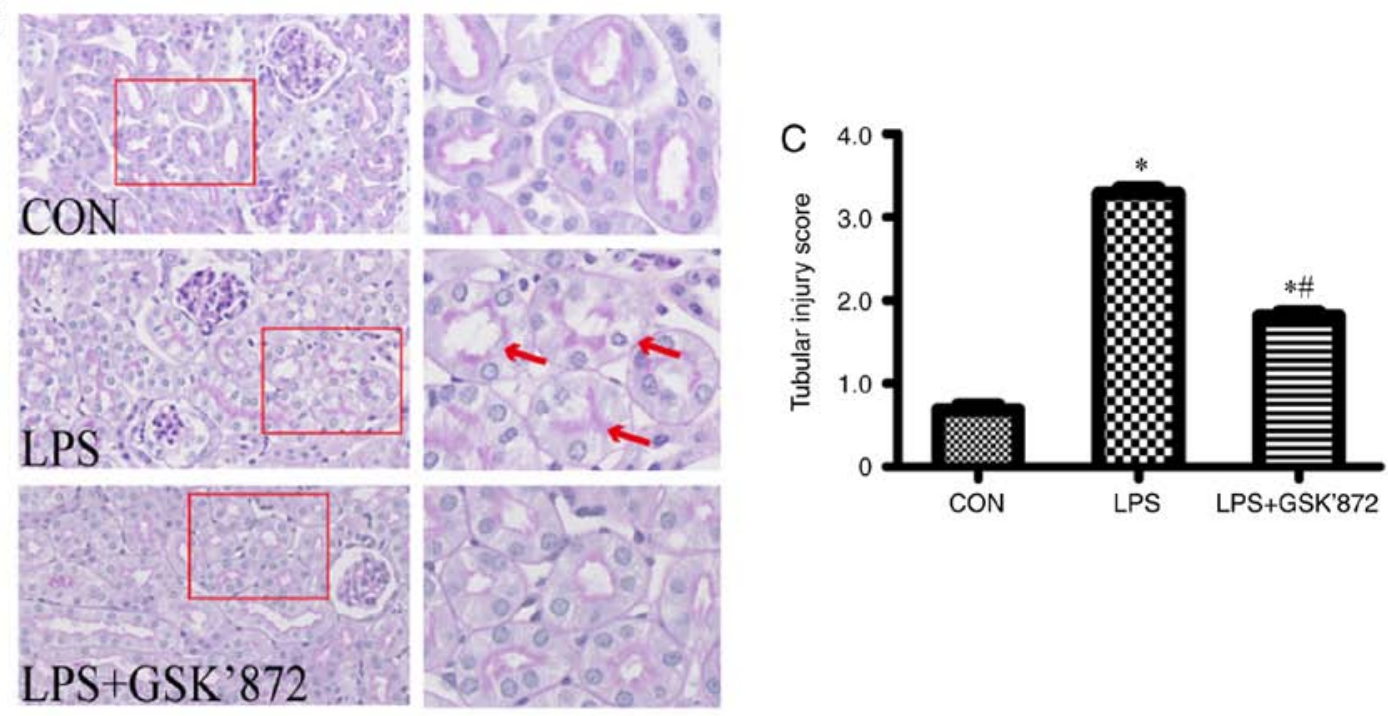

\section{LPS+GSK' 872}
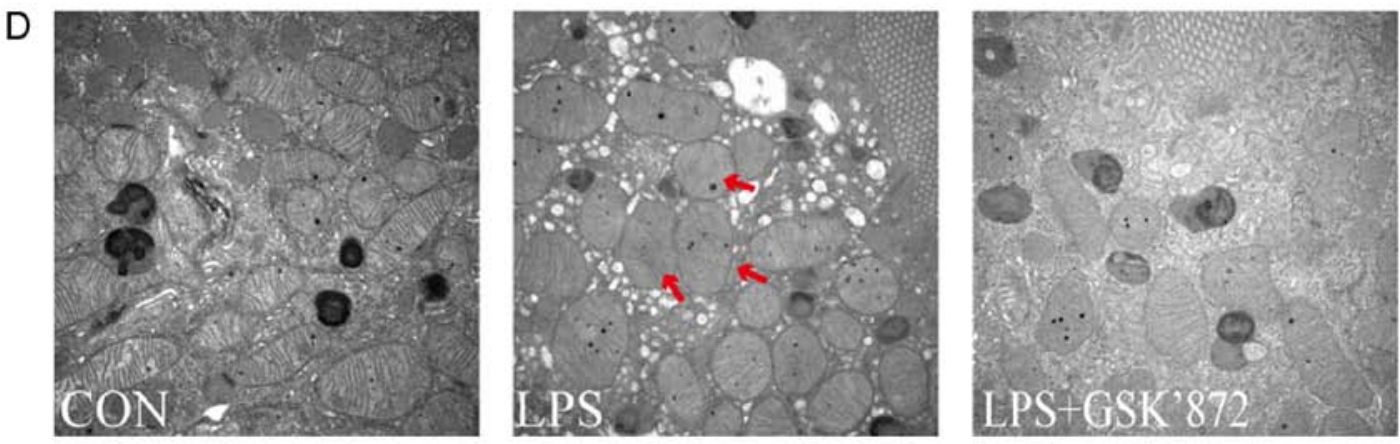

Figure 1. Effect of GSK'872 on renal function and pathological changes in LPS-induced acute kidney injury. C57BL/6 mice were randomly divided into three groups $(\mathrm{n}=6)$. Mice in the LPS group were treated with LPS intraperitoneally $(10 \mathrm{mg} / \mathrm{kg})$ for $24 \mathrm{~h}$. Mice in the GKS'872 group were intraperitoneally injected with the RIPK3 inhibitor GSK'872 $(5 \mu \mathrm{M} / \mathrm{kg})$ for 30 min prior to LPS exposure. (A) Serum BUN and creatinine were determined in the three groups. (B) Representative images of periodic acid-Schiff-stained kidney sections. Magnification, x200 (inset, magnification, x400). The red arrows indicate vacuolar deformation and swelling of renal tubular epithelial cells. (C) Quantification of tubular injury. The percentage of injured renal tubules was determined for each animal by histology scoring as described in the materials and methods section. (D) Electron microscopy of mitochondria in mouse renal tubular epithelial cells (magnification $\mathrm{x} 10,000$ ). The red arrows point to swelling and deformation of mitochondria. ${ }^{*} \mathrm{P}<0.01$ vs. CON; ${ }^{\#} \mathrm{P}<0.01$ vs. LPS. BUN, blood urea nitrogen; CON, control; LPS, lipopolysaccharide.

LPS-induced AKI increases tubular epithelial cell apoptosis and expression of RIPK3. C-caspase-3, a marker of apoptosis, was significantly increased in the kidney tissues of the LPS group (Fig. 2A). The expression of Bax, a proapoptotic member of the Bcl-2 family, was also significantly increased in the LPS group (Fig. 2B). RIPK3 expression was significantly increased in the kidney tissues of LPS-treated mice (Fig. 2C). In addition, the percentage of TUNEL-positive tubular epithelial cells in the LPS group was significantly higher than in the control group $(7.28 \pm 0.39 \%$ in the LPS group vs. $1.60 \pm 0.12 \%$ in the control group; $\mathrm{P}<0.001$; Fig. $2 \mathrm{D}$ and E). These results indicated that LPS induced tubular epithelial cell apoptosis.
Inhibition of RIPK3 reduces the level of apoptosis in tubular epithelial cells and improves renal function in mice with $L P S$-induced AKI. To establish the potential effect of RIPK3 on LPS-induced tubular epithelial cell apoptosis and AKI, GSK'872, a selective RIPK3 inhibitor, was administered to mice following LPS intervention. As shown in Fig. 2A-C, although LPS + GSK'872-treated mice did not exhibit reduced RIPK3 expression compared with the LPS group, GSK' 872 significantly inhibited the expression of C-caspase-3 and Bax. Immunofluorescent staining showed that the number of TUNEL-positive cells were signficantly decreased in the proximal renal tubular epithelial cells of mice in the LPS + GSK' 872 

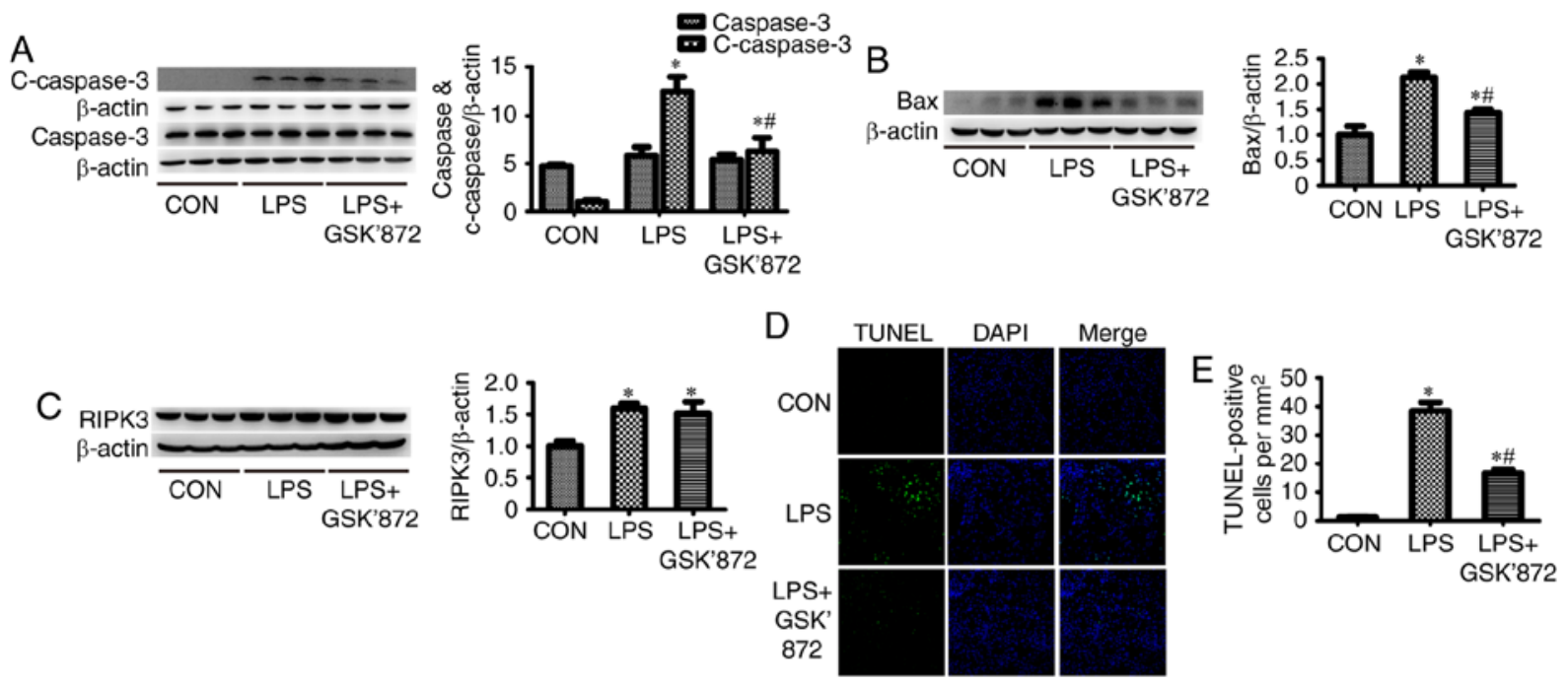

Figure 2. Expression levels of RIPK3 and tubular apoptosis in mice following LPS exposure ( $\mathrm{n}=6)$. Mice in the LPS group were treated with LPS intraperitoneally $(10 \mathrm{mg} / \mathrm{kg})$ for $24 \mathrm{~h}$. Mice in the GKS' 872 group were intraperitoneally injected with the RIPK3 inhibitor GSK' $872(5 \mu \mathrm{M} / \mathrm{kg})$ for $30 \mathrm{~min}$ prior to LPS exposure. (A) Western blot analysis for the expression of C-caspase-3 and full-length caspase-3 in mice from the different treatment groups. C-caspase-3 and full-length caspase-3 were from different membranes. (B) Western blot analysis for the expression of Bax in mice from the different treatment groups. (C) Western blot analysis for the expression of RIPK3 in mice from the different treatment groups. (D) TUNEL staining of renal tissue frozen sections from the different treatment groups. (E) Quantification of TUNEL-positive cells in the different treatment groups. ${ }^{*} \mathrm{P}<0.01$ vs. CON; "P $<0.01$ vs. LPS. C-caspase-3, cleaved caspase-3; CON, control; LPS, lipopolysaccharide; RIPK3, receptor-interacting protein kinase 3.
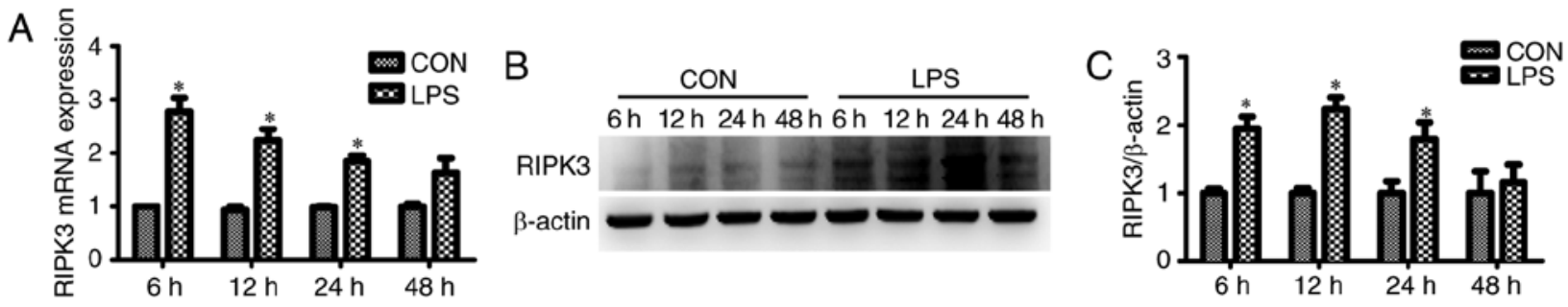

Figure 3. LPS increases the expression of RIPK3 in renal tubular epithelial cells in a time-dependent manner. (A) RIPK3 mRNA expression in renal tubular epithelial cells stimulated with $40 \mu \mathrm{g} / \mathrm{ml}$ LPS for 6, 12, 24 or $48 \mathrm{~h}$. (B) RIPK3 protein expression in renal tubular epithelial cells treated with LPS for 6, 12 , 24 or 48 h. (C) Quantification of RIPK3 protein expression. * $\mathrm{P}<0.01$ vs. respective CON. RIPK3, receptor-interacting protein kinase 3; CON, control; LPS, lipopolysaccharide.

group compared with those in the LPS group $(4.97 \pm 0.22 \%$ in the LPS + GSK'872 group vs. 7.28 $\pm 0.39 \%$ in the LPS group; $\mathrm{P}<0.001$; Fig. 2D and E). Mice treated with LPS+GSK'872 showed a visible improvement in histology (Fig. 1B). A semiquantitative evaluation of kidney sections showed that the tubular injury score decreased in the LPS + GSK'872 group $(1.81 \pm 0.05$ in the LPS + GSK'872 group vs. $3.29 \pm 0.06$ in the LPS group; $\mathrm{P}<0.001$; Fig. 1C). Mitochondrial injury was also alleviated by GSK'872 (Fig. 1D). GSK'872 significantly attenuated the increase in BUN $(52.32 \pm 5.15 \mathrm{mg} / \mathrm{dl}$ in the LPS + GSK'872 group vs. $80.59 \pm 3.74 \mathrm{mg} / \mathrm{dl}$ in the LPS group; $\mathrm{P}=0.001)$ and $\mathrm{SCr}(0.78 \pm 0.05 \mathrm{mg} / \mathrm{dl}$ in the LPS + GSK' 872 group vs. $1.26 \pm 0.13 \mathrm{mg} / \mathrm{dl}$ in the LPS group; $\mathrm{P}=0.003)$ in mice that had undergone LPS intervention (Fig. 1A).

RIPK3-mediates LPS-induced apoptosis in cultured renal tubular epithelial cells. The effect of RIPK3 on LPS-induced tubular epithelial cell apoptosis was assessed in vitro. It was found that the mRNA expression of RIPK3 was significantly increased in renal tubular epithelial cells as early as $6 \mathrm{~h}$ after LPS intervention (Fig. 3A). The protein expression of RIPK3 was induced $12 \mathrm{~h}$ after treatment with LPS (Fig. 3B and C). Renal tubular epithelial cell apoptosis was determined using flow cytometry. The number of Annexin V-positive cells (apoptotic cells) was significantly increased in the renal tubular epithelial cells that had undergone LPS treatment for $24 \mathrm{~h}(27.38 \pm 1.12 \%$ in the LPS group vs. $8.55 \pm 0.61 \%$ in the control group; $\mathrm{P}<0.001$; Fig. $4 \mathrm{~A}$ and $\mathrm{B}$ ). siRNA reduced the expression level of RIPK3 (Fig. 4E) and reduced tubular epithelial cell apoptosis $(27.38 \pm 1.12 \%$ in the LPS group vs. $13.95 \pm 1.12$ in the LPS + RIPK3-siRNA group; $\mathrm{P}<0.001$; Fig. 4A and B). LPS-induced apoptosis could also be inhibited by GSK'872 $(27.38 \pm 1.12 \%$ in the LPS group vs. $14.87 \pm 0.77 \%$ in the LPS + GSK'872 group; $\mathrm{P}<0.001$; Fig. 4A and B). The expression levels of the proapoptotic factor Bax and the apoptotic marker C-caspase-3 were also determined. Bax and C-caspase-3 were induced by LPS and reversed by GSK'872 or RIPK3-siRNA (Fig. 4C and D).

\section{Discussion}

In the present study it was found that renal tubular epithelial cell apoptosis, mitochondrial injury and RIPK3 upregulation 

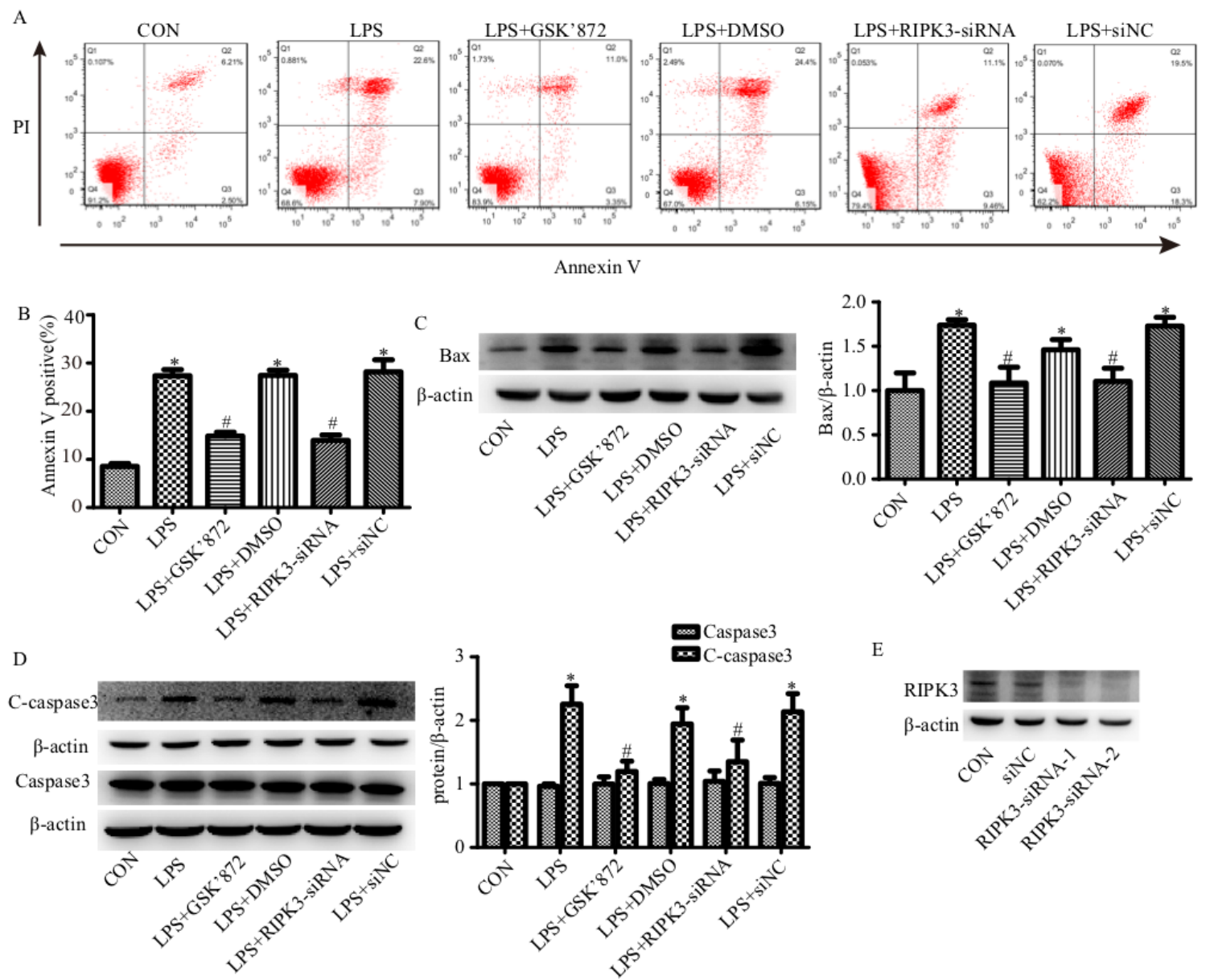

$\mathrm{E}$

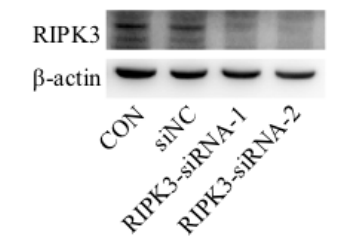

Figure 4. siRNA targeting RIPK3 and the RIPK3 inhibitor GSK' 872 reduce the levels of apoptosis in renal tubular epithelial cells following LPS stimulation. Mouse proximal renal tubular epithelial cells in the LPS group were stimulated with $40 \mu \mathrm{g} / \mathrm{ml}$ LPS for $24 \mathrm{~h}$. The RIPK3 kinase inhibitor GSK' 872 was added to cells $1 \mathrm{~h}$ prior to LPS stimulation in the LPS + GSK'872 group. The LPS + RIPK3-siRNA group was transfected with $5 \mathrm{nM}$ RIPK3-siRNA prior to LPS stimulation. The control group was treated with an equal volume of DMSO. (A) Levels of apoptosis were determined using flow cytometry. (B) Quantification of tubular epithelial cell apoptosis. (C) Western blot analysis for the expression of Bax in cultured tubular epithelial cells that have undergone different treatments. (D) Western blotting for the expression of C-caspase-3 and full-length Caspase-3 in different groups. C-caspase-3 and full-length caspase-3 were from different membrane. (E) The expression level of RIPK3 in siRNA-transfected renal tubular epithelial cells. " $\mathrm{P}<0.01$ vs. CON; "P $<0.01$ vs. LPS. PI, propidium iodide; CON, control; LPS, lipopolysaccharide; RIPK3, receptor-interacting protein kinase 3; siRNA, small interfering RNA; siNC, negative control siRNA; C-caspase-3, cleaved caspase-3.

were induced in LPS-induced AKI. Inhibiting RIPK3 using GSK'872 or reducing RIPK3 expression using siRNA reduced LPS-induced renal tubular epithelial cell apoptosis. GSK'872 functions by inhibiting the kinase activity of RIPK3 and does not reduce the expression of RIPK3. GSK'872 was found to alleviate LPS-induced renal tubular epithelial cell injury in vivo and in vitro by inhibiting the RIPK3 kinase activity. These results suggested that RIPK3 may mediate renal tubular epithelial cell apoptosis in LPS-induced AKI.

AKI is a well-documented complication of sepsis (1-3). LPS, also known as endotoxin, is an outer membrane component of gram-negative bacteria and has been identified as a major factor associated with the development of AKI. Renal tubular epithelial cell apoptosis is increasingly recognized as having an important role in the pathogenesis of septic or endotoxic AKI $(1,4,8)$. A previous study reported renal tubular epithelial cell apoptosis in septic AKI patients (26). In sepsis, LPS promotes the secretion of proinflammatory cytokines, nitric oxide and eicosanoids by binding to the monocyte differentiation antigen CD14/TLR4/lymphocyte antigen 96 receptor complex in various cell types, especially immunocytes, resulting in multiple organ dysfunction and AKI (1). Previous studies have shown that LPS could directly lead to renal tubular cell injury and AKI by binding to TLR4 (6,27-29). Consistent with previous studies $(6,9-11)$, the present study found that LPS induced renal tubular epithelial cell apoptosis in vitro and in vivo. However, the mechanisms of LPS-induced tubular epithelial cell apoptosis are not completely understood. In the present study, a novel mechanism of LPS-induced tubular epithelial cell apoptosis was investigated.

RIPKs are a group of threonine/serine protein kinases with a conserved kinase domain and distinct non-kinase regions (12). RIPKs are known to be important sensors of intracellular and extracellular stresses and to participate in different biological processes, including cell death signaling and inflammation pathways (12-14). RIPK3 is known to mediate necroptosis, a type of regulated necrosis. Activated RIPK3 could phosphorylate the mixed-lineage kinase domain-like protein, leading to plasma membrane rupture $(30,31)$. RIPK3-mediated necroptosis has been reported in ischemia/reperfusion and 
cisplatin-induced AKI (21,32-34). LPS activates RIPK3 by binding to TLR4 in fibroblasts (35). Consistent with a previous study on septic AKI (22), RIPK3 was upregulated in tubular epithelial cells in the present study. However, it was found that RIPK3 mediated renal tubular epithelial cell apoptosis. Several previous studies have also demonstrated the proapoptotic effect of RIPK3 (36-41). The effect of the RIPK3 inhibitor GSK'872 on apoptosis is concentration-dependent. Similar to RIPK3 deficiency, low-concentrations of GSK'872 (0.04-1 $\mu \mathrm{M})$, which binds to the RIPK3 kinase domain and inhibits kinase activity with a high specificity, prevents apoptosis in mouse bone-marrow-derived macrophages, peritoneal macrophages and fibroblasts $(35,42)$. However, previous studies reported that high-concentrations of GSK'872 (3-10 $\mu \mathrm{M})$, resembling a RIPK3-kinase-inactive mutant (D161N), could induce apoptosis in mouse cells by altering the conformation of RIPK3 $(15,18,19,36,42)$. In the present study, a low concentration of GSK'872 $(0.5 \mu \mathrm{M})$ significantly attenuated renal tubular cell apoptosis in vitro, consistent with the protective effect of RIPK3 knockdown. Therefore, the present study indicated that RIPK3 may be a new target for reducing renal tubular epithelial cell apoptosis and improving AKI.

To further explore the mechanisms of RIPK3-mediated renal tubular cell apoptosis induced by LPS, the expression of Bax was also investigated. Bax is a proapoptotic member of the Bcl-2 family. Previous studies have demonstrated that Bax translocates to the mitochondria and forms hetero- and homo-oligomers within the mitochondrial outer membrane, leading to the release of apoptosis-inducing proteins (43-45). In addition, Bax-deficient mice were found to be resistant to apoptosis (46). RIPK3-induced Bax upregulation has been reported recently (47-49). In the present study, Bax protein expression was significantly increased in renal tubular epithelial cells following LPS stimulation and this effect was abrogated by the downregulation of RIPK3 expression or the inhibition of RIPK3 kinase activity. It was therefore speculated that RIPK3 may mediate renal tubular epithelial cell apoptosis by upregulating the expression of Bax.

In conclusion, the present study demonstrated that the expression of RIPK3 was increased in LPS-induced AKI and that this mediated LPS-induced renal epithelial cell apoptosis. The proapoptotic effect of RIPK3 may function by upregulating the expression of Bax. The present study also revealed that low concentration GSK'872 inhibited LPS-induced renal epithelial cell apoptosis and attenuated AKI. Therefore, inhibiting RIPK3 may be a potential therapeutic strategy to treat septic AKI. However, further studies are required to determine the molecular mechanism underpinning the RIPK3/Bax pathway.

\section{Acknowledgements}

Not applicable.

\section{Funding}

The present study was supported by the National Natural Science Foundation of China (grant nos. 81570609 and 81770667) and Natural Science Foundation of Guangdong Province (grant nos. 2016A030313767 and 2018A0303130284).

\section{Availability of data and materials}

The datasets used and/or analyzed during the current study are available from the corresponding author on reasonable request.

\section{Authors' contributions}

SZ, RL and XL designed the study and wrote the manuscript. WD and YW performed the pathological evaluations. HY, WW, CL and ZY performed the animal experiments. LZ, YC, $\mathrm{XZ}, \mathrm{ZL}, \mathrm{MZ}$ and SL performed the in vitro experiments. All authors read and approved the final manuscript.

\section{Ethics approval and consent to participate}

All animal procedures conformed to the protocols of the Guangdong Academy of Medical Sciences and were approved by the ethics committee for the experimental use of animals at Guangdong Provincial People's Hospital.

\section{Patient consent for publication}

Not applicable.

\section{Competing interests}

The authors declare that they have no competing interests.

\section{References}

1. Zarjou A and Agarwal A: Sepsis and acute kidney injury. J Am Soc Nephrol 22: 999-1006, 2011

2. Emlet AD, Shaw AD and Kellum JA: Sepsis-associated AKI: Epithelial cell dysfunction. Semin Nephrol 35: 85-95 2015.

3. Mårtensson RB and Bellomo R: Sepsis-induced acute kidney injury. Crit Care Clin 31: 649-660, 2015.

4. Zarbock A, Gomez H and Kellum JA: Sepsis-induced acute kidney injury revisited: Pathophysiology, prevention and future therapies. Curr Opin Crit Care 20: 588-595, 2014.

5. Gotts JE and Matthay MA: Sepsis: Pathophysiology and clinical management. BMJ 353: i1585, 2016.

6. Stasi A, Intini A, Divella C, Franzin R, Montemurno E, Grandaliano G, Ronco C, Fiaccadori E, Pertosa GB, Gesualdo and LCastellano G: Emerging role of lipopolysaccharide binding protein in sepsis-induced acute kidney injury. Nephrol Dial Transplant 32: 24-31, 2017.

7. Plotnikov EY, Brezgunova AA, Pevzner IB, Zorova LD, Manskikh VN, Popkov VA, Silachev DN and Zorov DB: Mechanisms of LPS-induced acute kidney injury in neonatal and adult rats. Antioxidants (Basel) 7: pii: E105, 2018.

8. Havasi A and Borkan SC: Apoptosis and acute kidney injury. Kidney Int 80: 29-40, 2011.

9. Zhao H, Liu Z, Shen H, Jin S and Zhang S: Glycyrrhizic acid pretreatment prevents sepsis-induced acute kidney injury via suppressing inflammation, apoptosis and oxidative stress. Eur J Pharmacol 781: 92-99, 2016.

10. Rousta AM, Mirahmadi SM, Shahmohammadi A, Nourabadi D, Khajevand-Khazaei MR, Baluchnejadmojarad T and Roghani M: Protective effect of sesamin in lipopolysaccharide-induced mouse model of acute kidney injury via attenuation of oxidative stress, inflammation, and apoptosis. Immunopharmacol Immunotoxicol 40: 423-429, 2018.

11. Su Z, Yu P, Sheng L, Ye J and Qin Z: Fangjifuling ameliorates lipopolysaccharide-induced renal injury via inhibition of inflammatory and apoptotic response in mice. Cell Physiol Biochem 49: 2124-2137, 2018.

12. Zhang D, Lin J and Han J: Receptor-interacting protein (RIP) kinase family. Cell Mol Immunol 7: 243-249, 2010.

13. Declercq W, Vanden Berghe T and Vandenabeele P: RIP kinases at the crossroads of cell death and survival. Cell 138: 229-232, 2009. 
14. Witt A and Vucic D: Diverse ubiquitin linkages regulate RIP kinases-mediated inflammatory and cell death signaling. Cell Death Differ 24: 1160-1171, 2017.

15. Meylan ET and Tschopp J: The RIP kinases: Crucial integrators of cellular stress. Trends Biochem Sci 30: 151-159, 2005.

16. Sun X, Lee J, Navas T, Baldwin DT, Stewart TA and Dixit VM: RIP3 a novel apoptosis inducing kinase. J Biol Chem 274: 16871-16875, 1999.

17. Pazdernik NJ, Donner DB, Goebl MG and Harrington MA: Mouse receptor interacting protein 3 does not contain a caspase recruiting or a death domain but induces apoptosis and activates NF-kappaB. Mol Cell Biol 19: 6500-6508 1999.

18. Kasof GM, Prosser JC, Liu D, Lorenzi MV and Gomes BC: The RIP-like kinase, RIP3, induces apoptosis and NF-kappaB nuclear translocation and localizes to mitochondria. FEBS Lett 473: 285-291, 2000.

19. Feng S, Ma L, Yang Y and Wu M: Truncated RIP3 (tRIP3) acts upstream of FADD to induce apoptosis in the human hepatocellular carcinoma cell line QGY-7703. Biochem Biophys Res Commun 347: 558-565, 2006.

20. Xu Y, Ma H, Shao J, Wu J, Zhou L, Zhang Z, Wang Y, Huang Z, Ren J, Liu S, et al: A role for tubular necroptosis in cisplatin-induced AKI. J Am Soc Nephrol 26: 2647-2658, 2015.

21. Sureshbabu A, Patino E, Ma KC, Laursen K, Finkelsztein EJ, Akchurin O, Muthukumar T, Ryter SW, Gudas L, Choi AMK and Choi ME: RIPK3 promotes sepsis-induced acute kidney injury via mitochondrial dysfunction. JCI Insight 3: pii: 98411, 2018.

22. Shashaty MG, Reilly JP, Sims CA, Holena DN, Qing D, Forker CM, Hotz MJ, Meyer NJ, Lanken PN, Feldman HI, et al: Plasma levels of receptor interacting protein kinase-3 (RIP3), an essential mediator of necroptosis, are associated with acute kidney injury in critically Ill trauma patients. Shock 46: 139-143, 2016.

23. Brooks C, Wei Q, Cho SG and Dong Z: Regulation of mitochondrial dynamics in acute kidney injury in cell culture and rodent models. J Clin Invest 119: 1275-1285, 2009.

24. Schmittgen TD and Livak KJ: Analysis of relative gene expression data using real-time quantitative PCR and the 2(-Delta Delta C(T)) method. Methods 25: 402-408, 2001.

25. Lerolle N, Nochy D, Guérot E, Bruneval P, Fagon JY, Diehl JL and Hill G: Histopathology of septic shock induced acute kidney injury: Apoptosis and leukocytic infiltration. Intensive Care Med 36: 471-478, 2010

26. Shi M, Zeng X, Guo F, Huang R, Feng Y, Ma L, Zhou L and Fu P: Anti-inflammatory pyranochalcone derivative attenuates LPS-induced acute kidney injury via inhibiting TLR4/NF-kappaB pathway. Molecules 22: pii: E1683, 2017.

27. Nakano D, Doi K, Kitamura H, Kuwabara T, Mori K, Mukoyama M and Nishiyama A: Reduction of tubular flow rate as a mechanism of oliguria in the early phase of endotoxemia revealed by intravital imaging. J Am Soc Nephrol 26: 3035-3044, 2015.

28. Watts BA III, George T, Sherwood ER and Good DW: Monophosphoryl lipid a induces protection against LPS in medullary thick ascending limb through a TLR4-TRIF-PI3K signaling pathway. Am J Physiol Renal Physiol 313: F103-F115, 2017.

29. Sun L, Wang H, Wang Z, He S, Chen S, Liao D, Wang L, Yan J, Liu W, Lei X and Wang X: Mixed lineage kinase domain-like protein mediates necrosis signaling downstream of RIP3 kinase. Cell 148: 213-227, 2012.

30. Cho YS, Challa S, Moquin D, Genga R, Ray TD, Guildford M and Chan FK: Phosphorylation-driven assembly of the RIP1-RIP3 complex regulates programmed necrosis and virus-induced inflammation. Cell 137: 1112-1123, 2009.

31. Linkermanna A, Bräsen JH, Dardingd M, Jin MK, Sanz AB, Heller JO, De Zen F, Weinlich R, Ortiz A, Walczak H, et al: Two independent pathways of regulated necrosis mediate ischemia-reperfusion injury. Proc Natl Acad Sci USA 110: 12024-12029 2013.
32. Liu W, Chen B, Wang Y, Meng C, Huang H, Huang XR, Qin J, Mulay SR, Anders HJ, Qiu A, et al: RGMb protects against acute kidney injury by inhibiting tubular cell necroptosis via an MLKL-dependent mechanism. Proc Natl Acad Sci USA 115: E1475-E1484, 2018.

33. von Mässenhausen A, Tonnus W, Himmerkus N, Parmentier S, Saleh D, Rodriguez D, Ousingsawat J, Ang RL, Weinberg JM, Sanz AB, et al: Phenytoin inhibits necroptosis. Cell Death Dis 9: 359,2018

34. Kaiser WJ, Sridharan H, Huang C, Mandal P, Upton JW, Gough PJ, Sehon CA, Marquis RW, Bertin J and Mocarski ES: Toll-like receptor 3-mediated necrosis via TRIF, RIP3, and MLKL. J Biol Chem 288: 31268-31279, 2013.

35. Newton K, Dugger DL, Wickliffe KE, Kapoor N, de Almagro MC, Vucic D, Komuves L, Ferrando RE, French DM, Webster J, et al: Activity of protein kinase RIPK3 determines whether cells die by necroptosis or apoptosis. Science 343: 1357-1360, 2014.

36. Yabal M, Muller N, Adler H, Knies N, Groß CJ, Damgaard RB, Kanegane H, Ringelhan M, Kaufmann T, Heikenwälder M, et al: XIAP restricts TNF- and RIP3-dependent cell death and inflammasome activation. Cell Rep 7: 1796-1808, 2014.

37. Lawlor KE, Khan N, Mildenhall A, Gerlic M, Croker BA, D'Cruz AA, Hall C, Kaur Spall S, Anderton H, Masters SL, et al: RIPK3 promotes cell death and NLRP3 inflammasome activation in the absence of MLKL. Nat Commun 6: 6282, 2015.

38. Wicki S, Gurzeler U, Wei-Lynn Wong, Jost PJ, Bachmann D and Kaufmann T: Loss of XIAP facilitates switch to TNF $\alpha$-induced necroptosis in mouse neutrophils. Cell Death Dis 7: e2422, 2016.

39. Upton JW, Kaiser WJ and Mocarski ES: Virus inhibition of RIP3-dependent necrosis. Cell Host Microbe 7: 302-313, 2010.

40. Vandenabeele P, Declercq W, Van Herreweghe F and Vanden Berghe T: The role of the kinases RIP1 and RIP3 in TNF-induced necrosis. Sci Signal 3: re4, 2010.

41. Mandal P, Berger SB, Pillay S, Moriwaki K, Huang C, Guo H, Lich JD, Finger J, Kasparcova V, Votta B, et al: RIP3 induces apoptosis independent of pronecrotic kinase activity. Mol Cell 56: 481-495, 2014.

42. Kroemer D: The pathophysiology of mitochondrial cell death. Science 305: 626-629, 2004.

43. Bhatt K, Feng L, Pabla N, Liu K, Smith S and Dong Z: Effects of targeted $\mathrm{Bcl}-2$ expression in mitochondria or endoplasmic reticulum on renal tubular cell apoptosis. Am J Physiol Renal Physiol 294: F499-F507, 2008.

44. Bleicken S, Classen M, Padmavathi PV, Ishikawa T, Zeth K, Steinhoff HJ and Bordignon E: Molecular details of Bax activation, oligomerization, and membrane insertion. J Biol Chem 285: 6636-6647, 2010.

45. Wei Q, Dong G, Franklin J and Dong Z: The pathological role of Bax in cisplatin nephrotoxicity. Kidney Int 72: 53-62, 2007.

46. Wei Q, Dong G, Chen JK, Ramesh G and Dong Z: Bax and bak have critical roles in ischemic acute kidney injury in global and proximal tubule-specific knockout mouse models. Kidney Int 84 : 138-148, 2013.

47. Zhou Y, Li Y, Zhou B, Chen K, Lyv Z, Huang D, Liu B, Xu Z, Xiang B, Jin S, et al: Inflammation and apoptosis: Dual mediator role for toll-like receptor 4 in the development of necrotizing enterocolitis. Inflamm Bowel Dis 23: 44-56, 2017.

48. Liu PY, Chang DC, Lo YS, His YT, Lin CC, Chuang YC, Lin SH, Hsieh MJ and Chen MK: Osthole induces human nasopharyngeal cancer cells apoptosis through fas-fas ligand and mitochondrial pathway. Environ Toxicol 33: 446-453, 2018.

49. Zielinska E, Zauszkiewicz-Pawlak A, Wojcik M and Inkielewicz-Stepniak I: Silver nanoparticles of different sizes induce a mixed type of programmed cell death in human pancreatic ductal adenocarcinoma. Oncotarget 9: 4675-4697, 2017.

This work is licensed under a Creative Commons Attribution-NonCommercial-NoDerivatives 4.0 International (CC BY-NC-ND 4.0) License. 